\title{
Structural, Linear, and Nonlinear Optical and Mechanical Properties of New Organic L-Serine Crystal
}

\author{
K. Rajesh and P. Praveen Kumar \\ Department of Physics, Presidency College, Chennai 600005, Tamilnadu, India \\ Correspondence should be addressed to P. Praveen Kumar; ppkpresidency@gmail.com
}

Received 29 November 2013; Accepted 31 December 2013; Published 11 February 2014

Academic Editor: Iwan Kityk

Copyright (c) 2014 K. Rajesh and P. P. Kumar. This is an open access article distributed under the Creative Commons Attribution License, which permits unrestricted use, distribution, and reproduction in any medium, provided the original work is properly cited.

Nonlinear optical single crystal of organic amino acid L-Serine (LS) was grown by slow evaporation technique. Solubility study of the compound was measured and metastable zone width was found. Single crystal X-ray diffraction study was carried out for the grown crystal. The linear and nonlinear optical properties of the crystal were confirmed by UV-Vis analysis and powder SHG tester. FT-IR spectrum was recorded and functional groups were analyzed. Vickers' microhardness studies showed the mechanical strength of the grown crystal. Laser damage threshold value of the crystal was calculated. Photoconductivity studies reveal the conductivity of the crystal.

\section{Introduction}

Nonlinear optical (NLO) materials, with high frequency conversion efficiency have the most required properties for optical communication and optical storage devices, and numerous device applications [1, 2]. Amino acids family crystals possess high NLO efficiency because of their noncentrosymmetric space group and chiral carbon atom [3, 4]. Second order molecular nonlinearity can be enhanced by large delocalized $\pi$-electron system with strong donor and acceptor groups $[5,6]$. Amino acids contain a proton donor carboxyl acid $\left(\mathrm{CoO}^{-}\right)$group and the proton acceptor $\left(\mathrm{NH}_{2}{ }^{+}\right)$with them. Molecular hyperpolarizability $\beta$ is the basis of a strong second harmonic generation response. Organic molecules usually exhibit large $\beta$ value are certainly potential candidate molecules for the NLO materials [7]. Many organic amino acid single crystals, L-Arginine Acetate (LAA) [8], L-Arginine Phosphate (LAP) [9], L-Alanine Acetate, and L-Histidine Acetate, are reported earlier.

L-Serine is an organic amino acid and exists in a zwitterionic form. The crystal structure of L-Serine has been reported [10]. Some of L-Serine based crystals are L-Serine sodium nitrate (LSSN) [11], L-Serine formate (LSF) [12], L-Serine hydrochloride (LSHCL), and L-Serine acetate (LSA) [13], and they have been reported in recent years.

In the present study, a systematic investigation has been, carried out on the growth of L-Serine (LS) single crystal. Lattice parameter values of L-Serine were carried out. Solubility of LS in different solvents is described and the metastable zone width is found out from the curve. FT-IR reveals the various functional groups present in the crystal system. UVVis studies were carried out for the grown crystal and the absorbance of the crystal in the visible region is measured. Microhardness, photoconductivity, laser damage threshold (LDT), and NLO efficiency of the grown crystal were also measured.

\section{Materials and Methods}

2.1. Synthesis and Crystal Growth. Five grams of L-Serine (Merck) salt was taken and dissolved in double ionized distilled water and saturated solution of L-Serine was prepared. The $\mathrm{pH}$ value of the saturated solution is 3.7 and it was allowed to evaporate at room temperature. Good quality, highly transparent crystal of L-Serine was harvested in a period of 3 weeks. The photograph of as-grown L-serine single crystal is shown Figure 1. 


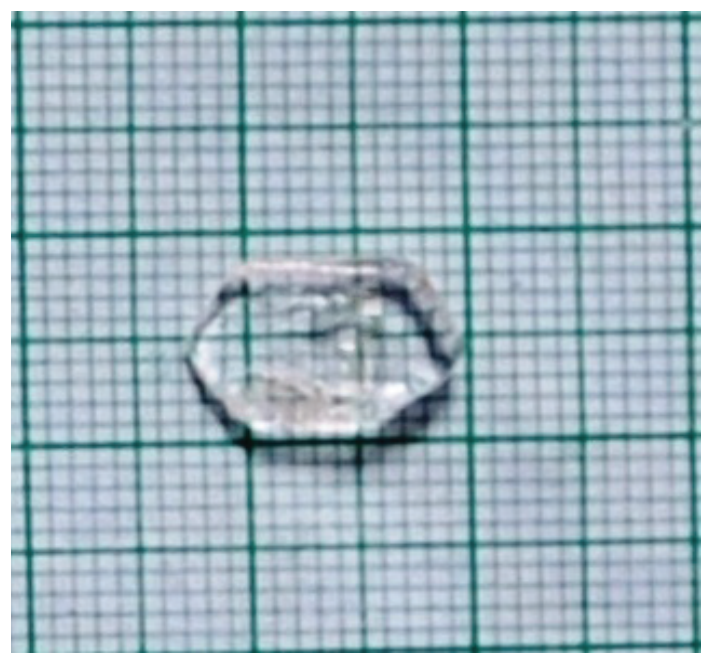

FIGURE 1: Photograph of as-grown L-Serine.

\section{Characterization Studies}

3.1. Solubility and Metastable Zone Width Measurement. The solubility of L-Serine was determined in the temperature range from $30^{\circ} \mathrm{C}$ to $60^{\circ} \mathrm{C}$ using water, acetone, and methanol as solvents. Initially, the temperature is fixed as $30^{\circ} \mathrm{C}$ and the LS salt is added step by step into $100 \mathrm{~mL}$ of deionized water and in other two solvents. The solution is stirred continuously till the supersaturation is achieved. Similarly, the amount of LS salt dissolved in $100 \mathrm{~mL}$ of water, acetone, and methanol at various temperatures has been determined. The solubility curves of the LS crystal were drawn and presented in Figure 2(a). It is concluded that solubility of LS in water is much higher than that of acetone and methanol solvents.

Metastable zone width is an essential parameter for the growth of large single crystal from solution. The prepared solution was stirred for about $6 \mathrm{hrs}$ continuously and the temperature is reduced at a rate of $5^{\circ} \mathrm{C} / \mathrm{hr}$. The temperature at which the first nucleation appeared is noted as nucleation temperature. The difference in nucleation temperature and saturated temperature is regarded to be the metastable zone width of the crystal [14].

The metastable zone width of LS in water solvent is given in Figure 2(b). From the graph, it is clear that metastable zone width decreases with the increase in temperature. Larger zone width at lower temperature shows that the LS crystal is a suitable material to grow by slow evaporation technique.

3.2. Single Crystal XRD Studies. The grown crystal of L-serine was subjected to single crystal XRD analysis to confirm the crystalline nature and to find the cell parameters by employing Enraf Nonius CAD 4 single crystal XRD diffractometer with $\operatorname{MoK} \alpha(0.71073 \AA)$. From the XRD data, it is observed that LS crystallizes in orthorhombic crystal system with the space group $\mathrm{P} 2{ }_{1} 2_{1} 2_{1}$. The lattice parameter values are in good agreement with the data reported earlier [10]. Table 1 shows the lattice parameter values of LS along with the reported values.
TABLE 1: Lattice parameter value of L-Serine.

\begin{tabular}{lcc}
\hline Crystal structure data & L-Serine & Reported value $[10]$ \\
\hline$a(\AA)$ & 8.532 & 8.5213 \\
$b(\AA)$ & 9.13 & 9.172 \\
$c(\AA)$ & 5.527 & 5.5847 \\
Volume $(V)\left(\AA^{3}\right)$ & 430.47 & 436.47 \\
$\alpha$ & $90^{\circ}$ & $90^{\circ}$ \\
$\beta$ & $90^{\circ}$ & $90^{\circ}$ \\
$\gamma$ & $90^{\circ}$ & $90^{\circ}$ \\
Crystal system & Orthorhombic & Orthorhombic \\
Space group & $\mathrm{P} 22_{1} 2_{1}$ & $\mathrm{P} 22_{1} 2_{1}$ \\
$z$ & 4 & 4 \\
\hline
\end{tabular}

3.3. FT-IR Spectrum. Fourier Transform Infrared analysis was carried out for the grown LS crystal to find the functional groups of the crystal. A fine powdered sample of LS was used for the FT-IR spectral analysis and the spectrum was recorded in the range $450 \mathrm{~cm}^{-1}-4000 \mathrm{~cm}^{-1}$ using $\mathrm{KBr}$ pellet technique. The recorded spectrum is shown in Figure 3.

The absorption peak at $3091 \mathrm{~cm}^{-1}$ is an indication of the presence of $\mathrm{NH}_{3}{ }^{+}$groups in the crystal. The peaks at $2733 \mathrm{~cm}^{-1}$ and $2566 \mathrm{~cm}^{-1}$ are attributed to the $\mathrm{C}-\mathrm{H}$ stretching mode vibration. The $\mathrm{COO}^{-}$symmetric stretching vibration modes are confirmed at the peaks $1402 \mathrm{~cm}^{-1}, 1336 \mathrm{~cm}^{-1}$, and $1371 \mathrm{~cm}^{-1}$. Asymmetric deformation of $\mathrm{NH}_{3}^{+}$is confirmed by the peak at $1597 \mathrm{~cm}^{-1}$. The strong absorption peak at $1630 \mathrm{~cm}^{-1}$ indicates the presence of primary amino acid group. The multiple combination and overtone bands extended the absorption of hydrogen bonded $\mathrm{N}-\mathrm{H}$ stretching vibration to $2000 \mathrm{~cm}^{-1}$ [15].

In the overtone region, there is a strong absorption peak at $2040 \mathrm{~cm}^{-1}$, which is assigned to the combination of asymmetrical $\mathrm{NH}_{3}{ }^{+}$bending vibration $\left(1630 \mathrm{~cm}^{-1}\right)$ and torsional oscillations of $\mathrm{NH}_{3}{ }^{+}$group $\left(516.92 \mathrm{~cm}^{-1}\right)$.

3.4. Linear and Nonlinear Optical Studies. The optical absorbance studies of LS crystal have been carried out between $190 \mathrm{~nm}$ and $500 \mathrm{~nm}$ ranges using UV-Vis spectrophotometer. The optical absorbance spectrum of L-Serine crystal is presented in Figure 4. From the spectrum, it is clear that the LS crystal is highly transparent in the entire visible region with the lower cutoff wavelength of $208 \mathrm{~nm}$. Transmittance of the crystal in the entire visible region suggests its suitability for the second harmonic generation [16].

The second harmonic efficiency of L-Serine crystal has been measured by Kurtz-Perry powder technique [17]. The SHG signal was confirmed by the emission of green light $(\lambda=$ $532 \mathrm{~nm}$ ) from the sample. The output signal of $46 \mathrm{mV}$ for LS crystal was obtained for an input of $30 \mathrm{~mJ} /$ pulse compared with the SHG output signal of standard KDP crystal of $55 \mathrm{mV}$ for the same input energy. The SHG efficiency of the grown LS crystal is 0.84 times that of KDP crystal. 


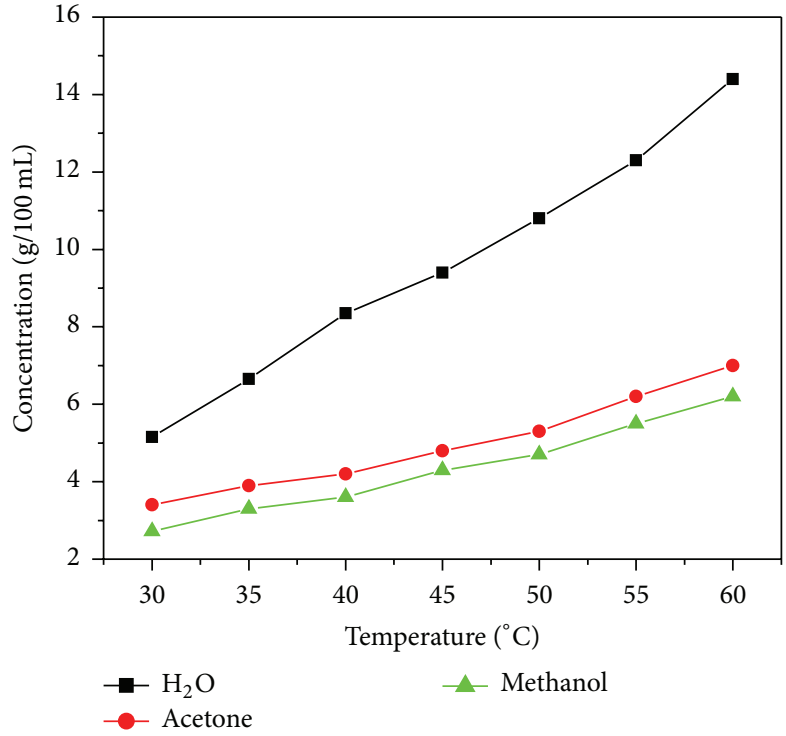

(a)

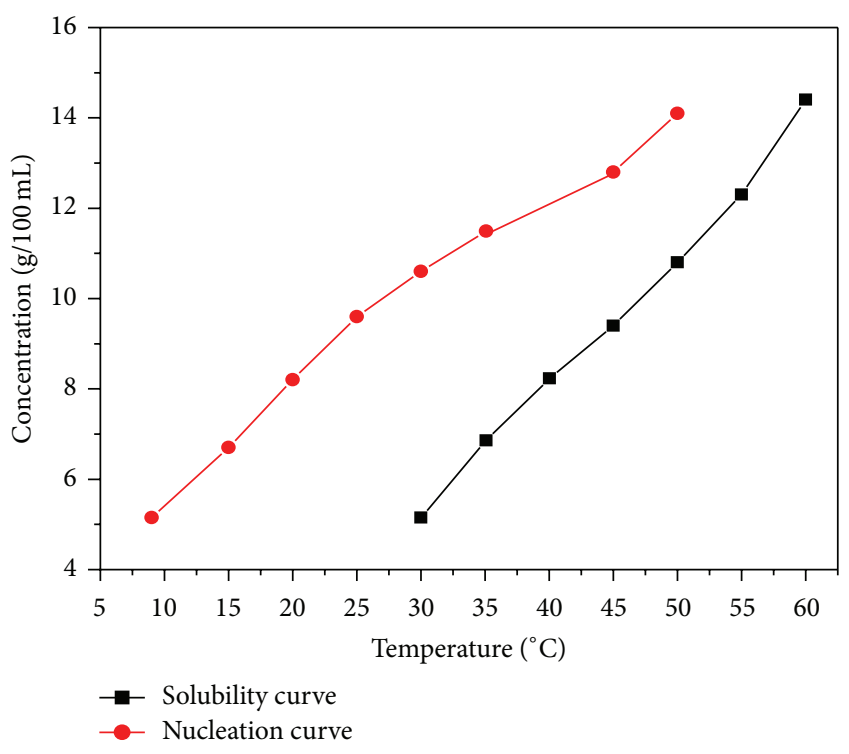

(b)

FIgURE 2: (a) Solubility curve of LS. (b) Metastable zone width curve of LS.

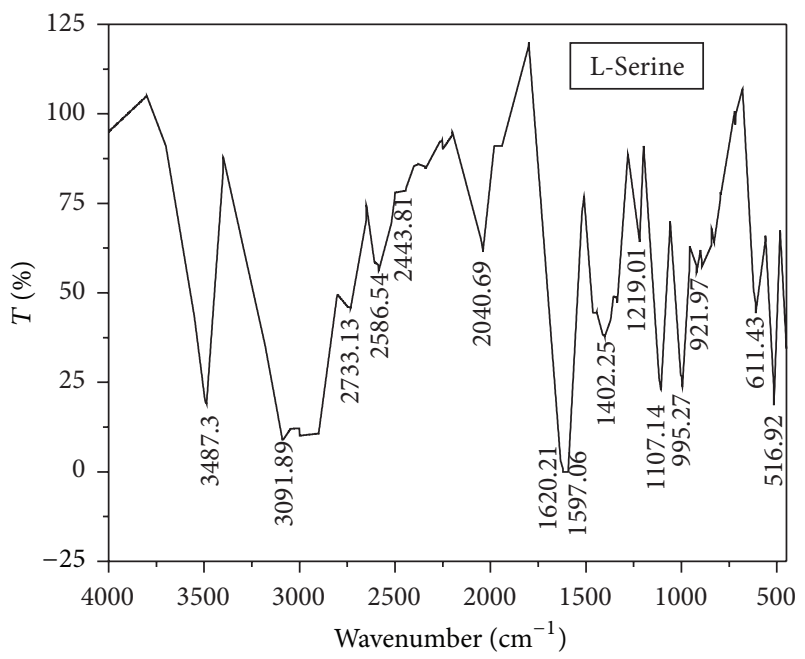

Figure 3: FT-IR spectrum of L-Serine.

3.5. Microhardness. Micro hardness test is the suitable method to find the mechanical property of the materials [18]. Mechanical strength of the crystal has been carried out using Vickers' micro hardness tester. Smooth surface of LS crystal is subjected to hardness studies at room temperature. For a time interval of $5 \mathrm{~s}$, different load is applied to the crystal. The microhardness number $H_{v}$ is calculated using the relation

$$
H_{v}=\frac{1.855 P}{d^{2}} \text { in } \mathrm{kg} / \mathrm{mm}^{2} \text {. }
$$

A graph between hardness number $H_{v}$ and applied load is drawn and shown in Figure 5. From the graph, it clear that the hardness increases with the increase in load. The hardness number varies for the planes $\left(\begin{array}{lll}1 & 0 & 0\end{array}\right)$ and $\left(\begin{array}{lll}0 & 1 & 0\end{array}\right)$ of the same applied load. The maximum $H_{v}$ for $\left(\begin{array}{lll}1 & 0 & 0\end{array}\right)$ plane is

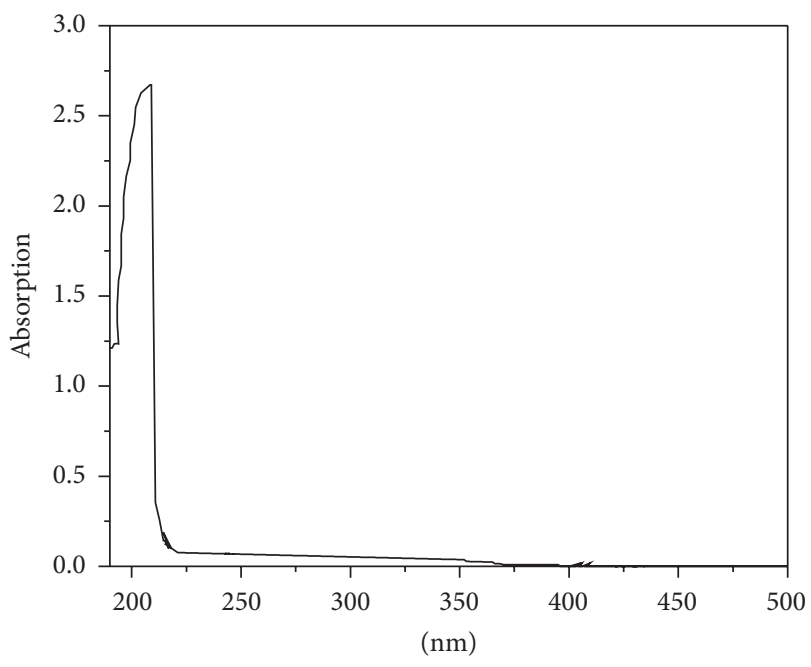

FIGURE 4: UV absorbance spectrum of L-Serine.

$42.7 \mathrm{~kg} / \mathrm{mm}^{2}$ for the load of $50 \mathrm{~g}$ and the $H_{v}$ for $\left(\begin{array}{lll}0 & 1 & 0\end{array}\right)$ plane is $57.8 \mathrm{~kg} / \mathrm{mm}^{2}$ for the load of $70 \mathrm{~g}$.

The result shows that the hardness for $\left(\begin{array}{lll}0 & 1 & 0\end{array}\right)$ plane is higher than $\left(\begin{array}{lll}1 & 0 & 0\end{array}\right)$ plane. Thus, it is clear that the LS crystal possesses anisotropy property. The anisotropy coefficient was calculated from the formula

$$
A=\frac{\nabla H v}{H v},
$$

where $\nabla H_{v}$ is the difference in hardness number and $H v$ is the maximum hardness number [19]. The anisotropy coefficient of the crystal is calculated as $26.12 \%$. By plotting $\log d$ versus $\log P$, the working hardness coefficient " $n$ " of the crystal is to be found, where $P$ is the applied load and $d$ is the average diagonal length. From the slope, " $n$ " value is calculated as 


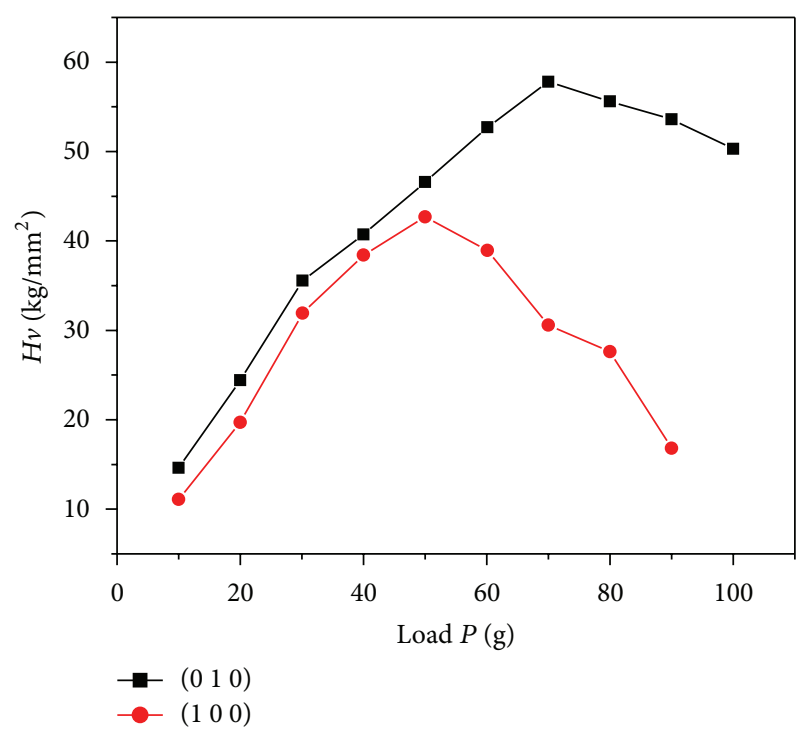

FIGURE 5: Vickers' microhardness plot of L-Serine.

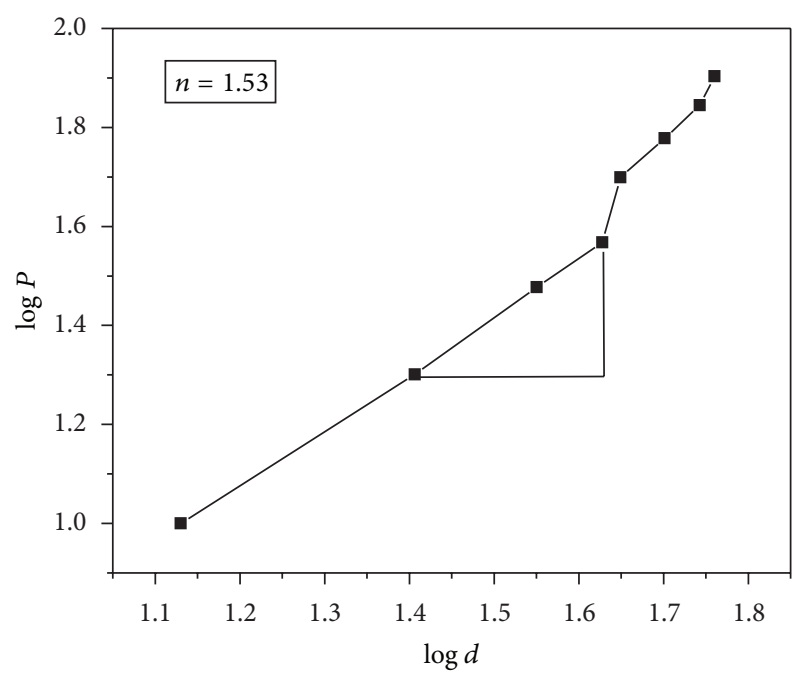

FIgURE 6: Meyer's plot of L-Serine.

1.53. According to Onitsch, $n$ lies between 1 and 1.6 for hard materials and $n$ is greater than 1.6 for soft materials [20]. Thus, LS belongs to hard material category (Figure 6).

3.6. Laser Damage Threshold (LDT) Studies. Laser damage is one of the main criteria for selecting NLO material, since in nonlinear process high intensities are involved. Well-polished surface of the crystal was subjected to Q switched Nd:YAG laser for $20 \mathrm{~ns}$ pulse width to do laser damage threshold study.

The output laser intensity is delivered to the sample. The energy density of the laser input beam for which the crystal gets damaged was recorded. The surface power density of the crystal was calculated using the following relation:

$$
P_{(d)}=\frac{E}{\tau A},
$$

TABLE 2: LDT value of the L-Serine with KDP and Urea.

\begin{tabular}{lc}
\hline Compound & LDT $\left(\mathrm{GW} / \mathrm{cm}^{2}\right)$ \\
\hline L-Serine & 2.17 \\
KDP & 0.20 \\
Urea & 1.50 \\
\hline
\end{tabular}

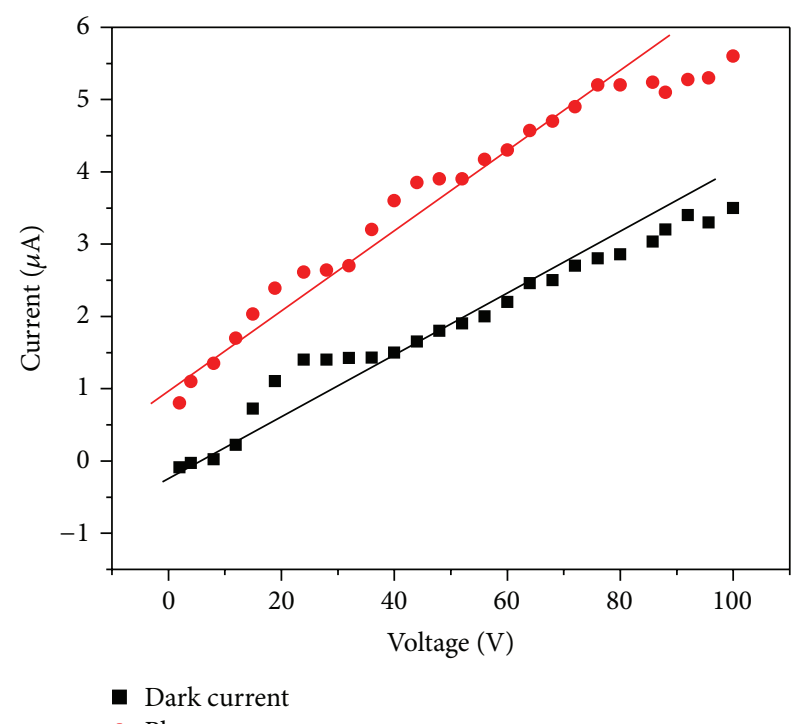

- Photo current

FIgURE 7: Photoconductivity plot of L-Serine.

where $P_{(d)}$ is the power density, $E$ is energy of the laser beam in $\mathrm{mJ}, \tau$ is the pulse width, and $A$ is the area of the circular spot size of the crystal. The calculated LDT value for the grown LS crystal is $2.17 \mathrm{GW} / \mathrm{cm}^{2}$. The laser damage threshold of LSerine is higher than KDP and Urea [21] and the values are shown in Table 2.

3.7. Photoconductivity Studies. Photoconductivity studies were carried out for the LS crystal using Keithley 485 picoammeter at room temperature. The dark current $\left(I_{d}\right)$ of the sample was measured using DC power supply and picoammeter. Photo current of the sample was measured using halogen lamp containing iodine vapor. DC supply is increased step by step from $10 \mathrm{~V}$ to $100 \mathrm{~V}$ and the photo current $\left(I_{p}\right)$ was measured.

Figure 7 shows the variation of photo current and dark current as a function of applied field. It is observed from the plot that dark current $\left(I_{d}\right)$ and photo current $\left(I_{p}\right)$ of the sample increase linearly with the applied field and the photo current is always greater than the dark current. Thus, the material exhibits positive photoconductivity [22].

\section{Conclusion}

Single crystal of L-Serine was grown by slow evaporation technique and the cell parameters of the crystal confirmed the material. LS crystallizes in orthorhombic crystal system. Solubility study and metastable zone width of the crystal have been found. Linear optical studies show the transparency of 
the crystal in the entire visible region. SHG studies confirm the nonlinearity of the grown crystal by the emission of green light and the SHG efficiency of the grown LS crystal is found to be 0.84 times that of KDP crystal. FT-IR spectrum of the crystal elucidates the presence of various functional groups in the crystal. The Vickers micro hardness study of the crystal was carried out and the crystal is found to be of hard material category. The grown crystal exhibits anisotropy. Photo conductivity studies reveal the positive photoconductivity of the crystal. The laser damage threshold of L-Serine is higher than KDP and Urea.

\section{Conflict of Interests}

The authors declare that there is no conflict of interests regarding the publication of this paper.

\section{References}

[1] H. O. Marey, L. F. Warrn, M. S. Webb, C. A. Ebbers, G. C. Kennedy, and G. C. Catella, "Second-harmonic generation in zinc tris(thiourea) sulfate," Applied Optics, vol. 31, no. 24, pp. 5051-5060, 1992.

[2] X. Q. Wang, D. Xu, D. R. Yuan et al., "Synthesis, structure and properties of a new nonlinear optical material: zinc cadmium tetrathiocyanate," Materials Research Bulletin, vol. 34, no. 12-13, pp. 2003-2011, 1999.

[3] M. Kitazawa, R. Higuchi, and M. Takahashi, "Ultraviolet generation at $266 \mathrm{~nm}$ in a novel organic nonlinear optical crystal: 1pyrrolidone-2-carboxylic acid," Applied Physics Letters, vol. 64, no. 19, p. 2477, 1994.

[4] L. Misoguti, A. T. Varela, F. D. Nunes et al., "Optical properties of L-alanine organic crystals," Optical Materials, vol. 6, no. 3, pp. 147-152, 1996.

[5] J. Zyss, "Hyperpolarizabilities of substituted conjugated molecules. III. Study of a family of donor-acceptor disubstituted phenyl-polyenes," The Journal of Chemical Physics, vol. 71, no. 2, p. $909,1979$.

[6] B. F. Levine, C. G. Bethea, R. D. Thermond, R. T. Lynch, and J. L. Berstein, "An organic crystal with an exceptionally large optical second-harmonic coefficient: 2-methyl-4-nitroaniline," Journal of Applied Physics, vol. 50, no. 4, pp. 2523-2527, 1979.

[7] P. S. Patil, S. M. Dharmaprakash, K. Ramakrishna, H. Fun, R. S. Kumar, and D. N. Rao, "Second harmonic generation and crystal growth of new chalcone derivatives," Journal of Crystal Growth, vol. 303, no. 2, pp. 520-524, 2007.

[8] P. P. Kumar, V. Manivannan, P. Sagayaraj, and J. Madhavan, "Growth and characterization of pure and doped NLO Larginine acetate Single crystals," Bulletin of Materials Science, vol. 32, no. 4, pp. 431-435, 2009.

[9] D. Xu, M. Jiang, and Z. Tan, "A new phase matchable nonlinear optic crystal L-arginine phosphate monohydrate," Acta Chimica Sinica, vol. 41, no. 6, pp. 570-573, 1983.

[10] S. A. Moggach, D. R. Allan, C. A. Morrison, S. Parsons, and L. Sawye, "Effect of Pressure on the crystal structure of LSerine-I and crystal structure of L-Serine-II at 5.4 Gpa," Acta Crystalographica B, vol. 61, part 1, pp. 58-68, 2005.

[11] S. Z. A. Ahamed, G. R. Dillip, L. Manoj, P. Raghavaiah, and B. D. P. Raju, "Growth and characterization of a new NLO material: L-serine sodium nitrate," Photonics Letters of Poland, vol. 2, no. 4, pp. 183-185, 2010.
[12] P. Krishnan, K. Gayathri, and G. Anbalagan, "Growth and characterization of L-serine formate nonlinear optical single crystal," AIP Conference Proceedings, vol. 1512, no. 1, p. 906, 2013.

[13] K. Rajesh, P. P. Kumar, A. Zamara, and A. Thirugnanam, "Growth, optical, mechanical and electrical properties of L-serine acetate: a promising semiorganic nonlinear optical crystal," AIP Conference Proceedings, vol. 1536, p. 759, 2013.

[14] T. Arumanayagam and P. Murugakoothan, "Studies on growth, spectral and mechanical properties of new organic NLO crystal: guanidinium 4-nitrobenzoate (GuNB)," Journal of Crystal Growth, vol. 362, pp. 304-307, 2013.

[15] R. M. Kumar, D. R. Babu, D. Jayaraman, R. Jayavel, and K. Kitamura, "Studies on the growth aspects of semi-organic L-alanine acetate: a promising NLO crystal," Journal of Crystal Growth, vol. 275, no. 1-2, pp. e1935-e1939, 2005.

[16] N. P. Zaitseva, L. N. Rashkovich, and S. V. Bogatyreva, "Stability of $\mathrm{KH}_{2} \mathrm{PO}_{4}$ and $\mathrm{K}(\mathrm{H}, \mathrm{D}){ }_{2} \mathrm{PO}_{4}$ solutions at fast crystal growth rates," Journal of Crystal Growth, vol. 148, no. 3, pp. 276-282, 1995.

[17] S. K. Kuurtz and T. T. Perry, "A powder technique for the evaluation of nonlinear optical materials," Journal of Applied Physics, vol. 39, no. 8, p. 3798, 1968.

[18] B. Lal, K. K. Bamzai, and P. N. Kotru, "Mechanical characteristics of melt grown doped $\mathrm{KMgF}_{3}$ crystals," Materials Chemistry and Physics, vol. 78, no. 1, pp. 202-207, 2003.

[19] A. Bhaskaran, C. M. Ragavan, R. Sankar, R. Mohankumar, and R. Jayavel, "Growth and characterization of semiorganic nonlinear optical tetrakis thiourea nickel chloride single crystals," Crystal Research and Technology, vol. 42, no. 5, pp. 477-482, 2007.

[20] E. M. Onitsch, "The present status of testing the hardness of materials," Microscope, vol. 95, p. 12, 1950.

[21] N. Vijayan, G. Bhagavannarayana, R. R. Babu, R. Gopalakrishnan, K. K. Maurya, and P. Ramasamy, "A Comparative study on solution and Bridgman grown single crystals of benzimidazole by high-resolution XRD, FTIR, microhardness, laser damage threshold and SHG measurements," Crystal Growth and Design, vol. 6, pp. 1542-1546, 2006.

[22] R. H. Bube, Photoconductivity of Solids, Wiley, New York, NY, USA, 1981. 

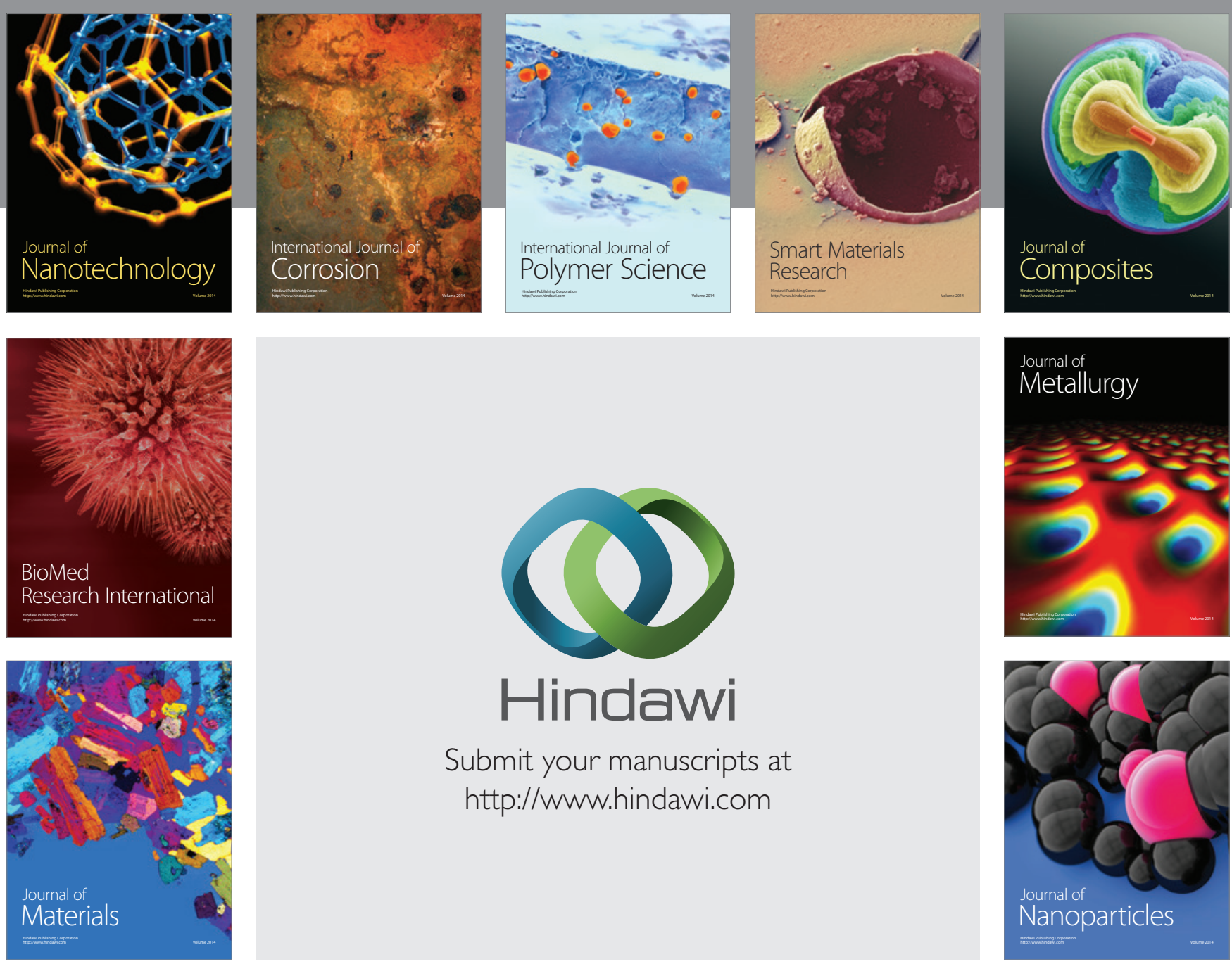

Submit your manuscripts at http://www.hindawi.com
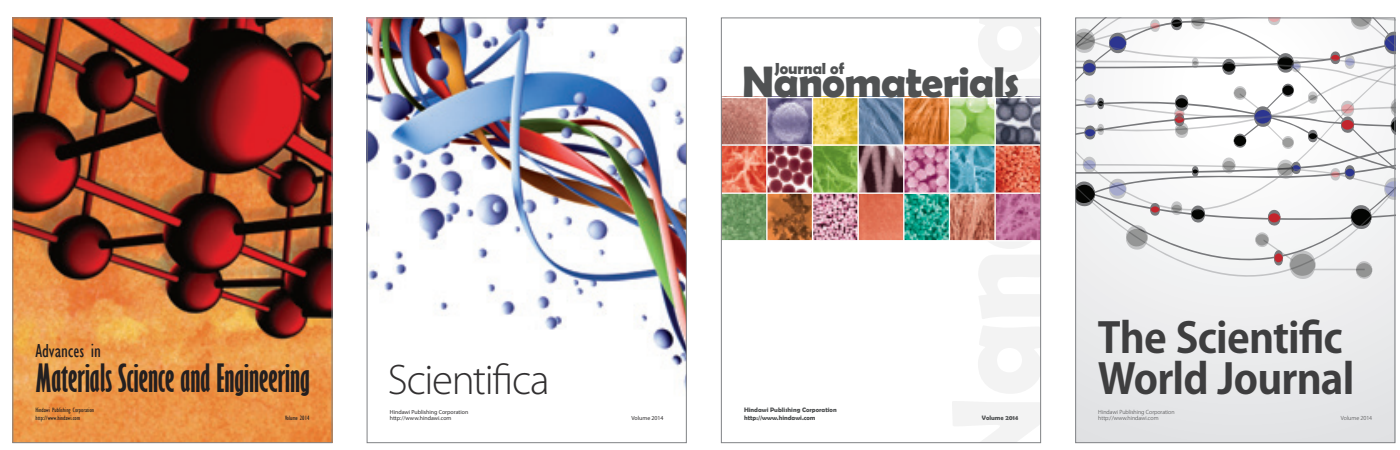

\section{The Scientific World Journal}
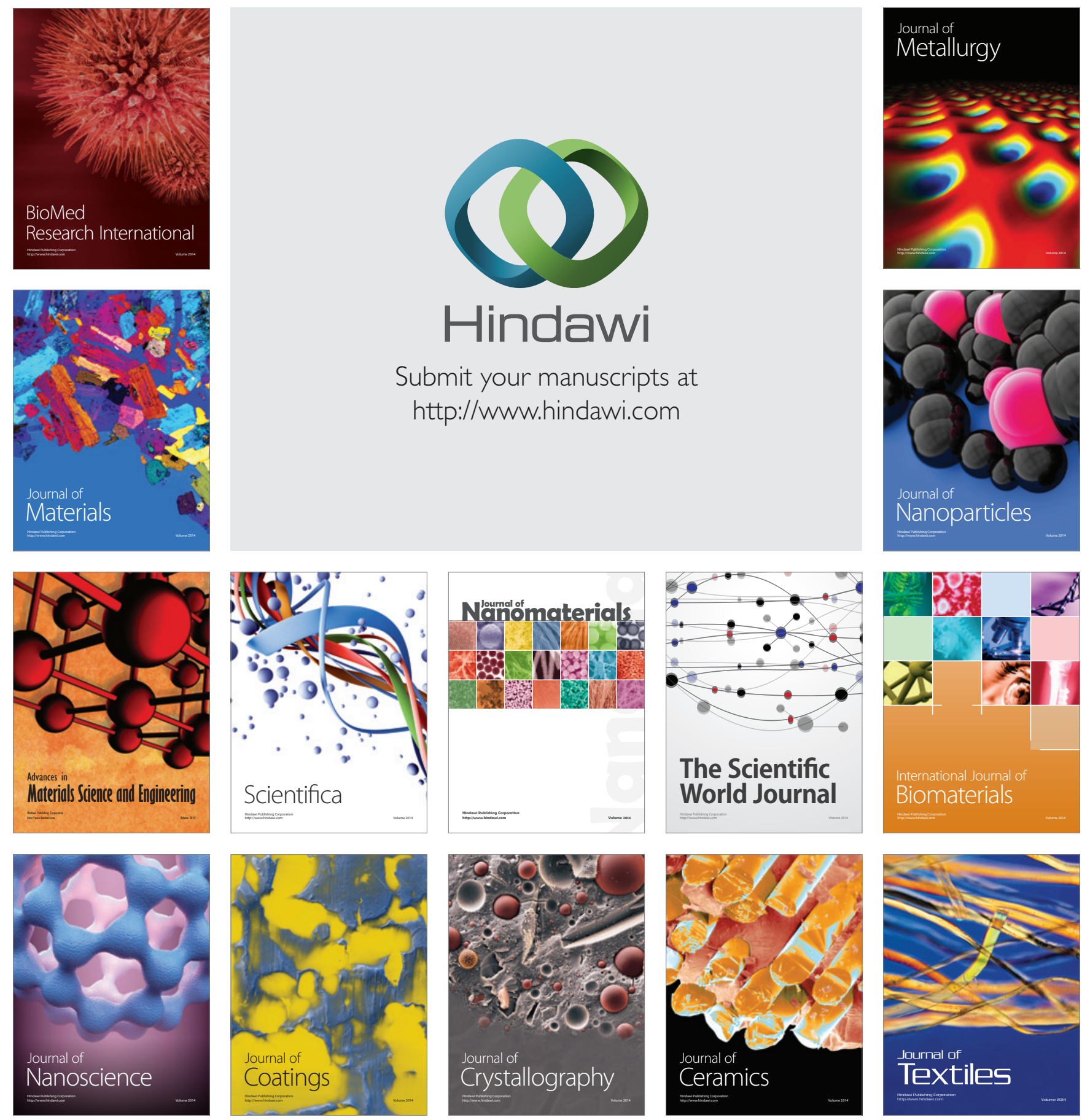